\title{
ANÁLISE DOS RISCOS DO PROJETO DE CONCESSÃO OU PARCERIA PÚBLICO-PRIVADA (PPP) EM MICRORREGIÕES DE ÁGUA E ESGOTO DA PARAÍBA
}

\section{ANALYSIS OF THE RISKS OF THE CONCESSION PROJECT OR PUBLIC-PRIVATE PARTNERSHIP (PPP) IN WATER AND SEWAGE MICRO-REGIONS OF PARAÍBA}

\author{
Jhersyka Barros Barreto ${ }^{(1)}$ \\ Arquiteta e Urbanista (UFAL), especialista em Educação e Meio Ambiente (IFAL), mestra e doutoranda em Engenharia \\ e Gestão de Recursos Naturais. Atua na área de Planejamento Urbano e Regional, com foco em Saneamento Básico. \\ Kainara Lira dos Anjos ${ }^{(2)}$ \\ Arquiteta e Urbanista (UFPE), possui Mestrado e Doutorado em Desenvolvimento Urbano pelo Programa de Pós- \\ graduação em Desenvolvimento Urbano (UFPE). Atualmente é professora adjunto do curso de arquitetura e urbanismo \\ da Universidade Federal de Campina Grande (UFCG). \\ Patrícia Hermínio Cunha Feitosa ${ }^{(3)}$ \\ Engenharia Civil (UFPB) e doutorado em Engenharia Agrícola (UFCG). Atualmente é professora associada I da \\ Universidade Federal de Campina Grande (UFCG). \\ Wilton Maia Velez ${ }^{(4)}$ \\ Geógrafo (UEPB), especialista em Geografia e Meio Ambiente. Atualmente, é Mestrando vinculado ao Programa de Pós- \\ Graduação em Engenharia e Gestão de Recursos Naturais (UFCG).
}

E-mail $^{(1)}$ : jhersykabarreto@gmail.com.

\section{RESUMO}

Na Paraíba, foram instituídas quatro Microrregiões de Água e Esgoto, através da Lei Complementar N 168/2021: Alto Piranhas, Borborema, Espinharas e Litoral. A estruturação de prestação regionalizada nos Estados brasileiros é uma exigência da Lei Federal $N^{\circ} 14.026 / 2020$, que inclui como uma das diretrizes para a alocação de recursos públicos federais e dos financiamentos com recursos da União ou geridos/operados por órgãos/entidades da União. Esse artigo visa analisar os riscos do Projeto de Concessão ou PPP do Governo da Paraíba em parceria com o BNDES, diante das Microrregiões de Água e Esgoto da Paraíba. Os principais resultados apontam que, caso a Microrregião do Litoral e Alto Piranhas sejam privatizadas, a sustentabilidade econômico-financeira da Companhia de Água e Esgoto da Paraíba (CAGEPA) pode ser comprometida, o que pode dificultar a manutenção e ampliação dos serviços de abastecimento de água e esgotamento sanitário nos demais municípios situados na Borborema e em Espinharas.

\begin{abstract}
In Paraíba, four Water and Sewerage Microregions were instituted through Complementary Law N ${ }^{\circ}$ 168/2021: Alto Piranhas, Borborema, Espinharas and Litoral. The structuring of regionalized provision in Brazilian states is a requirement of Federal Law $N^{\circ} 14.026 / 2020$, which includes as one of the guidelines for the allocation of federal public resources and financing with Union resources or managed/operated by Union bodies/entities. This article aims to analyze the risks of the Concession Project or PPP of the Government of Paraíba in partnership with the BNDES, in view of the Water and Sewerage Microregions of Paraíba. The main results point out that, in case the Litoral and Alto Piranhas Microregions are privatized, the economic-financial sustainability of the Paraíba Water and Sewerage Company (CAGEPA) may be compromised, which may hinder the maintenance and expansion of water supply and sewerage services in the other municipalities located in Borborema and Espinharas.
\end{abstract}

Palavras-chave: Regionalização do Saneamento. Privatização do Saneamento. Privatização da Água. Segurança Hídrica. Água e Saneamento.

Key words: Sanitation Regionalization. Privatization of Sanitation. Water Privatization. Water Security. Water and Sanitation 


\section{INTRODUÇÃO}

O acesso à água e ao saneamento são direitos humanos fundamentais, reconhecidos pela Organização das Nações Unidas (ONU), desde 2010. No Brasil, os serviços de abastecimento de água e esgotamento sanitário são prestadores, predominantemente, pela Administração Pública, por meio de Contratos de Programa ou Convênios com empresas estatais ou prestadores locais dos Municípios. Mas, em 2020, a Lei Federal No 14.026 vedou esse tipo de prestação e instituiu a obrigatoriedade de Concessão desses serviços por meio de Leilões. Essa mudança tende a ampliar a participação do setor privado na prestação desses serviços nos Estados brasileiros.

Na Paraíba, cerca de 90\% dos municípios são atendidos pela Companhia de Água e Esgoto da Paraíba (CAGEPA) e os demais por prestadores locais. De acordo com dados de 2015, 2017 e 2019 consultados no Sistema de Informações sobre Saneamento (SNIS), em 2021, mais de 70\% dos municípios paraibanos são deficitários, ou seja, não possuem Receitas Operacionais Diretas suficientes para subsidiar os seus serviços de abastecimento de água e esgotamento sanitário. O subsídio cruzado desempenha um papel relevante para a garantia desses serviços no Estado.

No entanto, a Lei Federal no 14.026/2020 alterou a Lei Federal $N^{o} 11.445 / 2007$, o que inviabilizou a aplicação do subsídio cruzado destinados a usuários determinados e destinados ao prestador de serviços de saneamento (BARRETO et al., 2021). Além disso, impôs a Regionalização do Saneamento para os Estados, com o prazo até 15 de julho de 2021. O que resultou na criação das Microrregiões de Água e Esgoto da Paraíba e suas respectivas estruturas de governança, através da Lei Complementar No 168/2021, que instituiu as seguintes Microrregiões: Alto Piranhas; Borborema; Espinharas; e Litoral.

Algumas Microrregiões de Água e Esgoto da Paraíba, em períodos de estiagem, apresentam queda significativa na disponibilidade hídrica, o que reflete no aumento da quantidade de municípios deficitários e em situação de insegurança hídrica, alguns chegam a declarar situação de calamidade pública, como nos casos recentes de Bananeiras e Solânea (G1 PB, 2021). Em relação aos aspectos climáticos, ambientais e de disponibilidade hídrica, os municípios da Microrregião do Litoral apresentam condições mais favoráveis por estarem situados, predominantemente, no Bioma da Mata Atlântica, que possui índices pluviométricos mais elevados. As demais Microrregiões estão situadas na Caatinga, com médias pluviométricas anuais inferiores a $800 \mathrm{~mm}$, apenas a Microrregião da Borborema apresenta uma pequena área de transição entre os Biomas citados.

A Lei No 14.026/2020 incluiu no Marco Regulatório do Saneamento Básico (Lei Federal 11.445/2007), como um dos princípios fundamentais, a prestação regionalizada dos serviços, com vistas à geração de ganhos de escala, garantia da universalização e da viabilidade técnica e econômico-financeira dos serviços. No entanto, apenas uma das quatro Microrregiões de Água e Esgoto da Paraíba apresenta viabilidade técnica e econômico-financeira dos serviços, que é a Microrregião do Litoral. Essa Microrregião concentra cerca de $61 \%$ da soma das Receitas Operacionais Diretas Totais (FN001) da Paraíba, considerando a média dessas receitas nos anos 2015, 2017 e 2019, enquanto as outras três Microrregiões somam 39\% (Barreto et al., 2021).

O Banco Nacional de Desenvolvimento Econômico e Social (BNDES) e o Governo do Estado da Paraíba firmaram parceria para a estruturação de Projeto de Concessão ou Parceria Púplico-Privada (PPP) da prestação de serviços públicos de abastecimento de água e esgotamento sanitário, bem como de gestão operacional, em 93 municípios do Estado da Paraíba, que estão situados nas Microrregiões do Alto Piranhas e do Litoral (BNDES, 2021), o que corresponde a 41,7\% dos municípios paraibanos. Os outros 58,3\% estão situados na Borborema e em Espinharas, que ficaram de fora do Projeto. O BNDES e o Governo do Estado não consideram as problemáticas e peculiaridades locais, que já afetam a Paraíba e podem ser agravadas caso haja a Concessão ou PPP em determinadas 
Microrregiões e/ou municípios, que concentram as maiores Receitas Operacionais Diretas do Estado.

O objetivo desse artigo é analisar os riscos do Projeto de Concessão ou PPP do Governo da Paraíba em parceria com o BNDES, diante da proposta de definição das Microrregiões de Água e Esgoto da Paraíba. Além disso, visa alertar para os riscos da privatização regionalizada nos Estados brasileiros e desmonte das empresas estatais para justificar processos de desestatização dessas empresas, com foco no caso da Paraíba e da Companhia de Água e Esgoto da Paraíba (CAGEPA).

\section{METODOLOGIA}

Trata-se de um estudo de caso sobre as Microrregiões de Água e Esgoto da Paraíba e o Projeto de Concessão ou PPP, que está em curso. Segundo Yin (2015), um estudo de caso é uma investigação empírica de um fenômeno contemporâneo dentro do contexto da vida real. Inclui abordagens específicas de coleta de dados e análise, com descrição de aspectos relevantes do caso.

A coleta de dados foi realizada através da Série Histórica do Sistema de Informações sobre Saneamento (SNIS, 2021), onde foram consultados informações e indicadores nos anos de 2015, 2017 e 2019. Os indicadores utilizados para a discussão desse trabalho foram: Indicador de Desempenho Financeiro (IN012) e Índice de Suficiência de Caixa (IN101). As informações foram estruturadas quanto a situação dos municípios, deficitários, os que não alcançaram desempenho financeiro satisfatório e tiveram insuficiência de caixa, ou superavitários, os que tiveram um desempenho financeiro satisfatório e suficiência de caixa. Essas informações foram organizadas em um quadro, onde constam os percentuais dos municípios deficitários e superavitários de cada Microrregião em relação ao total de municípios paraibanos.

\section{1. Área de Estudo}

As Microrregiões de Água e Esgoto da Paraíba foram definidas pelo Governo do Estado, a partir do Estudo Técnico (FUNDACE, 2021) desenvolvido pela Fundação para Pesquisa e Desenvolvimento da Administração, Contabilidade e Economia (FUNDACE). Os municípios paraibanos foram distribuídos entre as Microrregiões propostas nesse estudo e instituídas pela Lei Complementar Nº168/2021: Alto Piranhas, que possui 38 municípios com uma população total de 437 mil pessoas, Borborema, que abrange 84 municípios e população total de 1,2 milhões de pessoas, Espinharas, com 46 municípios e população total de 463 mil pessoas, e do Litoral, que possui 55 municípios e uma população total de 1,8 milhões de pessoas (Figura 1).

Figura 1 - Microrregiões de Água e Esgoto da Paraíba.

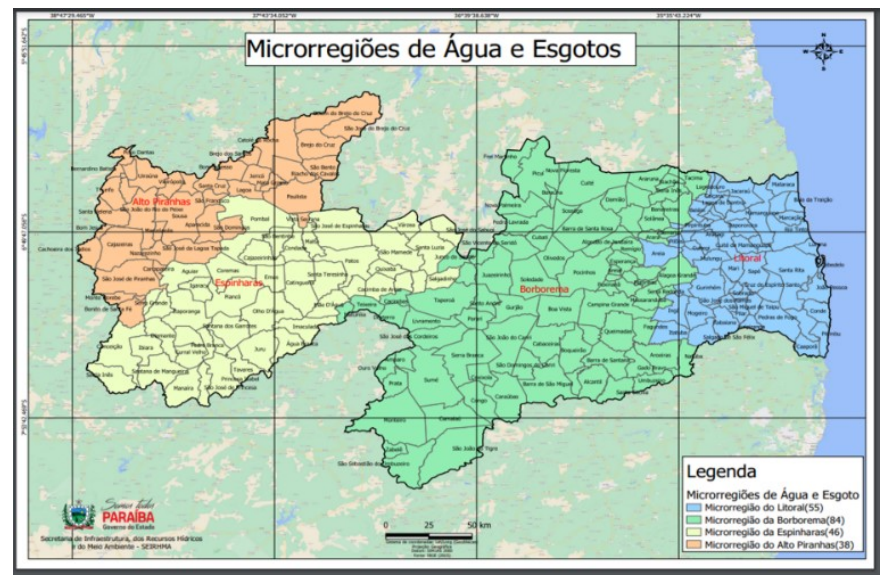

Fonte: PARAÍBA, 2021. 
Embora o Estudo Técnico (FUNDACE, 2021) tente atribuir semelhanças entre as Microrregiões, o Litoral e Alto Piranhas apresentam maiores potenciais socioeconômicos e aspectos ambientais mais favoráveis, enquanto Espinharas e Borborema possuem municípios em situações socioeconômicas e ambientais mais complexas e desfavoráveis em relação a disponibilidade hídrica e qualidade da água. Alto Piranhas e Litoral são as únicas Microrregiões que apresentam potencial para gerar Receita Operacional Direta de Água Exportada (FN007), em Alto Piranhas essa receita foi de 5,8 milhões de reais, em 2019, e no Litoral foi de 50 mil reais, nesse mesmo ano (SNIS, 2021).

Além disso, o Projeto de Integração do Rio São Francisco (PISF) já tem gerado impactos positivos no aumento do volume hídrico de açudes de algumas dessas Microrregiões e na qualidade da água, sobretudo em Alto Piranhas, por onde passa o Eixo Norte, que leva água para outros Estados (Ceará e Rio Grande do Norte). Por outro lado, Borborema e Espinharas são as mais afetadas pelo alto risco de desertificação devido às extensas áreas degradadas e aos baixos índices pluviométricos (PAE, 2011).

\section{RESULTADOS E DISCUSSÃO}

Considerando o período em estudo, Alto Piranhas (6\%) e Litoral (61\%) somam, em média, 67\%das Receitas Operacionais Diretas (FN001) da Paraíba, Borborema apresenta 25\% e Espinharas apenas $8 \%$. O SNIS calcula o FN001 a partir da soma das seguintes receitas: Receita Operacional Direta de Água (FN002), Receita Operacional Direta de Esgoto (FN003), Receita Operacional Direta de Água Exportada (Bruta ou Tratada) (FN007) e Receita Operacional Direta - Esgoto Bruto Importado (FN038).

A CAGEPA presta serviços de abastecimento de água e/ou esgotamento sanitário em cerca de 200 municípios paraibanos do total de 223 municípios. Caso haja a privatização com a Concessão privada da prestação desses serviços em Alto Piranhas e no Litoral, haverá uma perda significativa na Receita Operacional Direta Total da empresa. O que pode comprometer a sustentabilidade econômicofinanceira da CAGEPA e, também, a manutenção e ampliação dos serviços de abastecimento de água e esgotamento sanitário nos demais municípios atendidos por ela (BARRETO et al., 2021).

Não se trata apenas de comprometer a sustentabilidade econômico-financeira da empresa pública, que presta o serviço de abastecimento de água em cerca de $90 \%$ dos municípios paraibanos, mas de tornar ainda mais vulneráveis a população desses municípios ao desabastecimento hídrico. $\mathrm{O}$ fato de três Microrregiões (Alto Piranhas, Borborema e Espinharas) estarem situadas no Bioma da Caatinga e enfrentarem longos períodos de estiagem, que interferem na disponibilidade hídrica dos açudes que abastecem seus municípios agrava ainda mais a situação, que já é crítica.

As peculiaridades locais e os condicionantes climáticos e socioeconômicos não podem ser descartados diante de ações e políticas públicas de planejamento regional do saneamento básico da Paraíba. Criar Microrregiões de Água e Esgoto sem viabilidade técnica e econômico-financeira é assumir os riscos de acentuar problemáticas e desigualdades já existentes. Privatizar as duas Microrregiões que apresentam condições ambientais mais favoráveis e potencialidades para o desenvolvimento socioeconômico é transferir para o setor privado uma receita que até então é utilizada para subsidiar os serviços de abastecimento de água e esgotamento sanitário em municípios deficitários, beneficiando todo o Estado. Com a privatização, há riscos de que esse recurso seja revertido em lucro para empresas e seus acionistas em detrimento de toda a população paraibana, caso deixe de subsidiar os serviços para assegurar os direitos humanos à água e ao saneamento pelos Municípios e populações mais vulneráveis socioeconomicamente.

O Litoral concentra o maior percentual de municípios superavitários do Estado, enquanto a 
Borborema concentra o maior percentual de municípios deficitários. Nos anos de baixa disponibilidade hídrica (2015 e 2017), devido ao longo período de estiagem, nota-se uma queda significativa no percentual de municípios paraibanos superavitários. Ou seja, o percentual de municípios que apresentam insuficiência de caixa para subsidiar os serviços de abastecimento de água e esgotamento sanitário aumenta nesse período e passa de $80 \%$ em relação ao total de municípios paraibanos (Quadro 1).

Quadro 1 - Percentual de municípios deficitários e superavitários.

\begin{tabular}{|c|c|c|c|c|c|c|c|c|c|}
\hline \multicolumn{5}{|c|}{ Indicador de Desempenho Financeiro (\%) } & \multicolumn{5}{|c|}{ Índice de Suficiência de Caixa (\%) } \\
\hline Microrregião & Situação & 2015 & 2017 & 2019 & Microrregião & Situação & 2015 & 2017 & 2019 \\
\hline \multirow{2}{*}{ Alto Piranhas } & Deficitários & 14,3 & 15,2 & 11,2 & \multirow{2}{*}{ Alto Piranhas } & Deficitários & 12,6 & 14,8 & 11,7 \\
\hline & Superavitários & 2,7 & 1,8 & 5,8 & & Superavitários & 4,5 & 2,2 & 5,4 \\
\hline \multirow{2}{*}{ Borborema } & Deficitários & 36,3 & 34,5 & 29,6 & \multirow{2}{*}{ Borborema } & Deficitários & 34,1 & 34,5 & 30,9 \\
\hline & Superavitários & 1,3 & 3,1 & 8,1 & & Superavitários & 3,6 & 3,1 & 6,7 \\
\hline \multirow{2}{*}{ Espinharas } & Deficitários & 19,3 & 18,8 & 16,6 & \multirow{2}{*}{ Espinharas } & Deficitários & 18,8 & 18,8 & 16,1 \\
\hline & Superavitários & 1,3 & 1,8 & 4,0 & & Superavitários & 1,8 & 1,8 & 4,5 \\
\hline \multirow{2}{*}{ Litoral } & Deficitários & 19,3 & 18,8 & 12,1 & \multirow{2}{*}{ Litoral } & Deficitários & 18,8 & 15,2 & 11,2 \\
\hline & Superavitários & 5,4 & 5,8 & 12,6 & & Superavitários & 5,8 & 9,4 & 13,5 \\
\hline \multirow{2}{*}{ Paraíba } & Deficitários & 89,2 & 87,4 & 69,5 & \multirow{2}{*}{ Paraíba } & Deficitários & 84,3 & 83,4 & 70,0 \\
\hline & Superavitários & 10,8 & 12,6 & 30,5 & & Superavitários & 15,7 & 16,6 & 30,0 \\
\hline
\end{tabular}

Fonte: Elaborado com dados obtidos através do SNIS, 2021.

Além de concentrar a maioria dos municípios superavitários do Estado, a Microrregião do Litoral concentra, em média, 61\% das Receitas Operacionais Diretas Totais da Paraíba. É inconcebível a ideia de que a privatização dessa Microrregião, juntamente com a Microrregião do Alto Piranhas, por meio de Concessão ou PPP, seja positiva para um Estado com baixa disponibilidade hídrica como a Paraíba e para o seu povo, que já é tão afetado pelos condicionantes ambientais/hídricos.

\section{CONCLUSÕES}

A privatização dos serviços de saneamento fracassou em inúmeros países, municípios e regiões em todos os Continentes, dos mais desenvolvidos aos menos desenvolvidos. Há exemplos de remunicipalização dos serviços de água e esgotamento sanitário na França, Estados Unidos, Canadá, Espanha, Alemanha, China, Bolívia, Argentina, México, Uruguai, Colômbia, África do Sul e até no Brasil. (KISHIMOTO, LOBINA E PETITJEAN, 2015; KISHIMOTO, STEINFORT E PETITJEAN, 2020)

Itu, em São Paulo, remunicipalizou os seus serviços de abastecimento de água e esgotamento sanitário após constatar irregularidades cometidas pela empresa privada que detinha a concessão. No Estado do Tocantins, 92 municípios foram devolvidos ao Estado por não darem lucros a empresa privada que detém a concessão dos serviços e permaneceu apenas com 47 municípios. Vale ressaltar que, nos termos do contrato de privatização, a empresa se comprometia a cobrir efetivamente apenas os municípios do Estado do Tocantins com população superior a 50 mil habitantes, que correspondem aos municípios de Palmas, Araguaína, Gurupi e Porto Nacional. Dessa forma, a privatização comprometeu melhorias significativas de serviços de saneamento em municípios menores e áreas rurais, acentuando as desigualdades de acesso aos serviços e infraestruturas de saneamento entre os municípios de pequeno e grande porte (CORPORATE EUROPE OBSERVATORY E TRANSNATIONAL INSTITUTE, 2021)

Os cenários futuros do setor do saneamento são de muitos questionamentos e incertezas na Paraíba, assim como em outros Estados brasileiros. Será que os modelos de concessão e as modelagens da Regionalização do Saneamento desenvolvidos por Governos dos Estados em parceria com o BNDES 
consideram as problemáticas e peculiaridades locais desses Estados? A quem beneficiará a privatização regionalizada da prestação dos serviços de abastecimento de água e esgotamento sanitário por meio das Concessões?

Por mais que as Concessões gerem receitas diretas aos cofres do Governo do Estado com o valor pago na outorga, nada garante que essa receita será investida no setor de saneamento e que será distribuída de maneira proporcional e justa entre Estado e municípios envolvidos. Além disso, será um valor arrecadado uma única vez, enquanto os serviços estarão em concessão privada por cerca de 25 - 35 anos, considerando o período das concessões realizadas pelo BNDES em outros Estados.

As políticas públicas de Saneamento Básico precisam ser pautadas com base em estudos que garantam a viabilidade técnica, ambiental e econômico-financeira das ações de gestão e governança no setor de saneamento. Se essas ações podem acentuar problemáticas e situações de desigualdades e injustiças socioambientais frente ao acesso aos serviços de água e esgotamento sanitário, não são viáveis.

\section{AGRADECIMENTOS}

Agradecemos ao Programa de Pós-Graduação em Engenharia e Gestão de Recursos Naturais da Universidade Federal de Campina Grande (PPGEGRN - UFCG) e a Coordenação de Aperfeiçoamento de Pessoal de Nível Superior (CAPES) por tornarem viáveis pesquisas e trabalhos como este. E aos servidores e instituições públicas, que seguem resistindo às tentativas de desmonte e privatização dos serviços públicos pelo Ultraliberalismo que afeta o Brasil.

\section{REFERÊNCIAS}

BARRETO, J. B.; FEITOSA, P. H. C.; ANJOS, K. L. dos; VELEZ, W. M. Analysis of sanitation regionalization: Water scenarios and economic-financial (in)sustainability of the water and sewage microregions of Paraíba. Research, Society and Development, [S. 1.], v. 10, n. 10, p. 36, 2021. DOI: 10.33448/rsd-v10i10.18513. Disponível em: https://rsdjournal.org/index.php/rsd/article/view/18513. Acesso em: 29 aug. 2021.

BNDES. BNDES fará estudos para ampliar saneamento na Paraíba: Banco assinou contrato de estruturação de projeto com o Governo do Estado. Banco Nacional de Desenvolvimento Econômico e Social (BNDES). 14 de junho de 2021. Disponível em: https://www.bndes.gov.br/wps/portal/site/home/imprensa/noticias/conteudo/bndes-fara-estudospara-ampliar-\%20saneamento-na-paraiba

CORPORATE EUROPE OBSERVATORY E TRANSNATIONAL INSTITUTE. Walter Remunicipalisation Tracker. Acessado em: outubro de 2021. Disponível em: http://www.remunicipalisation.org/

KiShimoto, S.; Steinfort, L.; PetitJeAn, O. O Futuro é Público: pela Propriedade Democrática dos Serviços Públicos. pp. 275. 2020. Disponível em: https://www.tni.org/files/publication-downloads/o futuro e publico versao digital 02122021compactado.pdf

KISHIMOTO, S.; LOBINA, E.; PETITJEAN, O. (2015). Nosso futuro de água pública: A experiência global com remunicipalização. Recuperado de https://www.tni.org/files/download/ourpublicwaterfuture-1.pdf

PARAÍBA. Lei Complementar $\mathbf{n}^{\mathbf{0}}$ 168/2021, de 22 de junho de 2021. Disponível em https://auniao.pb.gov.br/servicos/arquivo-digital/doe/2021/junho/diario-oficial-23-06-2021.pdf 
BRASIL. Constituição da República Federativa do Brasil (1988). Brasília. Disponível em: www.planalto.gov.br/ccivil_03/constituicao/constituicao.htm

BRASIL. Lei Federal $\mathbf{N}^{\circ} \mathbf{1 0 . 7 6 8 / 2 0 0 3}$, de 19 de novembro de 2003. Disponível em http://www.planalto.gov.br/ccivil 03/Leis/2003/110.768.htm

BRASIL. Lei Federal No 9.984/2000, de 17 de julho de 2000. Disponível em http://www.planalto.gov.br/ccivil 03/leis/19984.htm

BRASIL. Lei Federal $\mathbf{N}^{\circ} \mathbf{1 1 . 4 4 5 / 2 0 0 7}$, de 05 de janeiro de 2007. Disponível em http://www.planalto.gov.br/ccivil 03/_ato2007-2010/2007/lei/111445.htm

BRASIL. Lei Federal $\mathbf{n}^{\mathbf{0}} \mathbf{1 2 . 3 0 5 / 2 0 1 0}, 02$ de agosto de 2010. Disponível em http://www.planalto.gov.br/ccivil_03/_ato2007-2010/2010/lei/112305.htm

BRASIL. Lei Federal $\mathbf{N}^{\mathbf{1}}$ 12.527/2011, de 18 de novembro de 2011. Disponível em http://www.planalto.gov.br/ccivil 03/ ato2011-2014/2011/lei/112527.htm

BRASIL. Lei Federal no 13.089/2015, de 12 de janeiro de 2015. Disponível em http://www.planalto.gov.br/ccivil 03/ ato2015-2018/2015/lei/113089.htm

BRASIL. Lei Federal $\mathbf{n}^{\mathbf{0}}$ 13.529/2017, de 04 de dezembro de 2017. Disponível em http://www.planalto.gov.br/ccivil 03/ ato2015-2018/2017/lei/113529.htm

BRASIL. Lei Federal $\mathbf{n}^{\mathbf{0}} \mathbf{1 4 . 0 2 6 / 2 0 2 0}$, de 15 de julho de 2020. Disponível em http://www.planalto.gov.br/ccivil 03/ ato2019-2022/2020/lei/114026.htm

FUNDACE. Estudo Técnico: Regionalização do Saneamento Básico: Paraíba. Microrregiões de Água e Esgoto da Paraíba. 2021. 214 p. Disponível em: https://paraiba.pb.gov.br/diretas/secretariade-infraestrutura-dos-recursos-hidricos-e-do-meio-ambiente/arquivos/consultapublica/ESTUDOREGIONALIZAOPARABA.pdf

G1 PB. Estado de calamidade pública é decretado em Solânea, na PB, por causa da crise hídrica: Na última semana, o município de Bananeiras também entrou em estado de calamidade pelo mesmo motivo. Globo Paraíba. 29 de setembro de 2021. Disponível em: https:/g1.globo.com/pb/paraiba/noticia/2021/09/29/estado-de-calamidade-publica-e-decretado-emsolanea-na-pb-por-causa-da-crise-hidrica.ghtml

PAE. Programa de ação estadual de combate à desertificação e mitigação dos efeitos da seca. João Pessoa: Secretaria de Estado dos Recursos Hídricos, do Meio Ambiente e da Ciência e Tecnologia. Superintendência de Administração do Meio Ambiente, 2011. Disponível em: http://www.mpce.mp.br/wp-content/uploads/2016/05/PROGRAMA-ESTADUAL-DE-COMBATEA-DESERTIFICA $\%$ C3\%87\%C3\%830.pdf

SNIS. Sistema Nacional de Informações sobre Saneamento. Download de dados do Saneamento na Paraíba (2015, 2017 e 2019). 2021. Disponível em: http://app4.mdr.gov.br/serieHistorica/

Yin, RK (2015). O estudo de caso. Porto Alegre: Bookman. 